\title{
Canários e a pesca no banco saariano (séculos XVII eXIIII)
}

Canarians and the fishing in the saharan bank (17th and 18th centuries)

Canariens et la pêche sur le banc saharien (XVIle et XVIIIe siècles)

Canarios y la pesca en el banco sahariano (siglos XVII y XVIII)

\section{Cezar Teixeira Honorato ${ }^{[1]}$}

\section{PÉREZ, Juan Manuel Santana; PÉREZ, German Santana. La pesca en el banco saha- riano: siglos XVII y XVIII. Madri: Catarata, 2014.}

$\Lambda$ cabo de ter acesso ao livro dos irmãos Santana Pérez, intitulado $L a$ pesca en el banco sahariano: siglos XVII y XVIII, que me causou uma agradável surpresa. Primeiramente, por ser um excelente exercício de história global em tempos de pós-modernidade. Em segundo lugar, por ser um tema pouquíssimo estudado: a pesca.

O livro parte de questões gratas à historiografia clássica ao se apoiar nos princípios da Escola dos Analles, em que a influência braudeliana ${ }^{2}$ é nítida, além dos pressupostos marxianos em suas mais variadas vertentes. Por tais razões, antes de ser um trabalho tão somente monográfico acerca da pesca, nos dá um painel primoroso do Antigo Regime, especialmente na Espanha dos séculos XVII e XVIII.

As grandes questões econômicas, políticas, sociais e culturais do período fluem ao longo do texto, colocando o tema da pesca saariana praticada nas ilhas Canárias no universo mais amplo em que se inseria a região na transição feudal-capitalista, inclusive em termos dos conflitos das monarquias ibéricas acerca do domínio do Atlântico Sul.

Mas talvez a maior contribuição em termos de uma história global esteja na própria estrutura do livro, na qual questões relacionadas com o mundo do trabalho, a dinâmica das empresas, as características das embarcações e da equipagem utilizada nos principais tipos de pesca, as questões geográficas e ecológicas que foram determinantes no avanço da exploração pesqueira na 
costa saariana desde o período estudado até os dias de hoje se articulam em um único texto.

A pesca, embora seja uma atividade humana existente desde os primórdios e envolvendo um grande número de pessoas, pouco tem sido observada pelos historiadores. Quando muito, atenta-se para os vários tipos de interdição e controles exercidos pelos Estados visando a controlá-la. Base da alimentação da sociedade, especialmente no caso do pescado salgado, movimentava negócios e trabalhadores com o registro de empresas pesqueiras desde o século XVI no arquipélago de Canárias, ganhando força ao longo dos séculos seguintes, objeto de estudo dos autores.

Os autores já apresentam na introdução o quadro geral do período, destacando-se a opção cronológica quando apontam que, no início do século XVII, foram realizadas as últimas incursões dos espanhóis, ainda com traços das cruzadas, especialmente nas ilhas na costa noroeste africana. Já a escolha do final do século XVIII até quando se aprova a Constituição espanhola de 1837 se deve não só à conjuntura mais global como à conclusão dos tratados de paz com os governantes africanos.

\section{A pesca, embora seja uma atividade humana existente desde os primórdios e envolvendo um grande número de pessoas, pouco tem sido observada pelos historiadores}

Ainda na introdução temos a descrição das principais fontes utilizadas na pesquisa. Nesse ponto, a surpresa é maior pela amplitude de arquivos pesquisados na França, na Inglaterra e, obviamente, nos vários arquivos espanhóis, com destaque para os das ilhas Canárias. A tipologia variada das fontes e as dificuldades de pesquisa inerentes ao trabalho com manuscritos aumenta ainda mais a importância do trabalho.

No primeiro capítulo, logo merecem destaque a análise detalhada do processo de trabalho da pesca com forte influência de uma excelente base antropológica e o cotidiano do trabalho pesqueiro, identificando cada categoria de trabalhadores envolvidos, suas principais tarefas e a remuneração específica de cada uma, mostrando como eram já bastante complexas as relações de produção no setor. A utilização de dados estatísticos acerca das viagens ocorridas no período, dos custos e da remuneração dos trabalhadores, inclusive de sua dieta alimentar durante o período no mar, torna o trabalho uma referência no tema.

O mesmo se pode dizer das empresas, que, após serem identificadas, tiveram um tratamento dos dados acerca de custos e lucros de algumas das excursões pesqueiras, da rede de negócios envolvendo a pesca, da salga, para, finalmente, terem apresentada a comercialização do pescado, culminando com 
a análise da contabilidade de uma companhia pesqueira, a Santo Domingo, dos primeiros anos do século XIX.

O segundo capítulo surpreende desde o início pelo domínio do conhecimento acerca da geografia do território de Berbería, local do banco saariano, que se localizava desde o Marrocos e o Saara Ocidental até Arguin, o território mais próximo do arquipélago das Canárias e com maior capacidade pesqueira, razão para os conflitos com os portugueses, que também exploravam a região.

Seguindo os autores, pode-se perceber que a costa africana é uma das regiões marítimas mais produtivas do planeta, pela maior quantidade de peixes passíveis de salga em razão de suas características físicas, envolvendo salinidade, temperatura das águas, correntes marítimas etc. para a pesca de merluza, cherne, bogas ou corvinas, ao contrário da pesca litorânea das Canárias, na qual merece destaque a pesca da sardinha.

No terceiro capítulo, após uma densa descrição do banco de Arguin, os autores investem no processo de ocupação/uso da região pesqueira desde o início do século XVI, inclusive com a apreensão de escravos e a questão da pesca pré-industrial na região. Embora discordemos de sua ideia acerca da própria definição de pesca pré-industrial, seus argumentos são bastante convincentes.

Um dos pontos altos do livro está no quarto capítulo, no qual são analisados o consumo e o comércio de pescado durante os séculos XVI e XVIII. Impressionam a acuidade e o ineditismo da questão da dieta alimentar da população - normalmente negligenciada pela historiografia tradicional -, bem como a importância do pescado fresco (o mais caro) ou salgado, além de lagostas e ostras, na complementação proteica da população, chamando a atenção para seu alto consumo entre os mais pobres.

Preparado de várias formas (frito, cozido, assado ou escabeche), o pescado, que era a base da alimentação dos mais pobres - sempre tendo as Canárias como referência -, não tinha muito prestígio entre os mais ricos, que valorizavam a carne, e, embora largamente consumido, nem era muito considerado como nutritivo pela população em geral, por sua leveza e facilidade de digestão.

Ainda nesse capítulo, merece destaque a impressionante análise da comercialização do pescado, os preços praticados e a preocupação da administração em garantir a qualidade das mercadorias que iam à venda e que seriam consumidas pela população, com uma quantidade impressionante de dados estatísticos extraídos das fontes.

Outra parte se abre com a análise da relação entre a produção de sal e as pescarias. A utilização do sal e a secagem do pescado, com destaque para peixes como o bacalhau, eram fundamentais para garantir sua vida útil com qualidade e para que todo o processo de transporte e comercialização não gerasse adulteração na qualidade, mesmo após longas e demoradas viagens. 
O que, para um leitor pouco atento, pode parecer uma digressão ao falar da questão do sal desde a Antiguidade, demonstra a profunda erudição dos autores, e mais, como a busca de uma história total é claramente apresentada no livro, demonstrando o quanto era fundamental a utilização do sal na pesca saariana, representando parte considerável dos custos de produção do pescado.

No sexto capítulo, a obra se dedica a analisar a emergência dos discursos da ilustração e sua relação com a pesca no banco saariano. Tais discursos foram fundamentais para a construção de projetos políticos para o setor. Por meio das iniciativas oficiais, dizem os autores, os ilustrados trataram de fomentar a pesca não só nas Canárias, mas em toda a Espanha, embora poucas das medidas surtiram o efeito esperado.

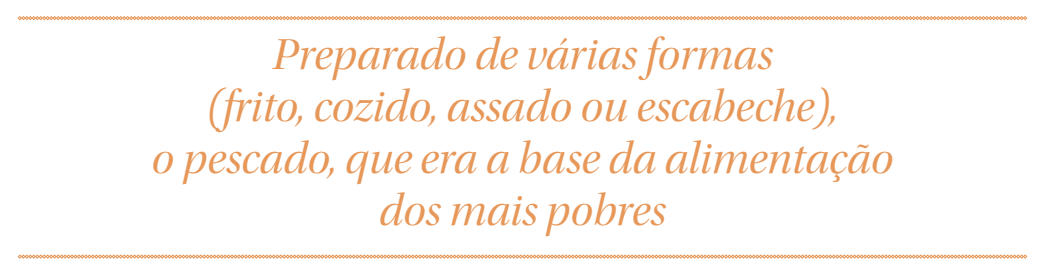

No último capítulo, os autores apontam ainda para novos projetos relacionados com a pesca que se tentou implementar na Espanha como um todo desde o final do século XVIII até o início do seguinte na região saariana. Entre eles, merece destaque a caça à baleia, seguindo o que ocorria em outros países da Europa, fundamental em razão do aumento mundial de seu azeite.

Outro projeto que entra em debate no mesmo período aponta para a preocupação da pesca predatória tanto nas Canárias quanto no banco saariano. A tentativa de proibir "redes de arrasto" com cota de malha pequena foi uma das medidas visando a evitar a diminuição da oferta pesqueira.

Finalmente, nas conclusões, os autores retomam muitas das questões desenvolvidas ao longo do denso texto e apontam a permanência nos dias de hoje de muitas das práticas da pesca e de barcos, em que pese o avanço da grande pesca industrial.

Por todas essas razões, acredito que se trata de um livro fundamental para o entendimento da história das ilhas Canárias, da África saariana, da própria dinâmica da sociedade da transição feudal-capitalista, considerando um tema ainda pouquíssimo estudado entre nós. Trata-se de uma obra madura de professores catedráticos da Universidade de Las Palmas de Gran Canarias. Pois tais razões, não temos dúvida de esse livro já se tornou uma referência fundamental para aqueles que queiram estudar tais assuntos, podendo servir de inspiração para os pesquisadores brasileiros em busca de novos temas e de "maneiras de fazer história". 